\title{
UMA RESENHA DE UM MESTRE: HOBSBAWM E A GLOBALIZAÇÃO, DEMOCRACIA E TERRORISMO
}

por Marcelo Paula de Melo*

HOBSBAWM, Eric J. Globalização, democracia e terrorismo. São Paulo: Companhia das Letras, 2007.

O historiador Eric J. Hobsbawm pode ser considerado um dos maiores pensadores ainda em ação, bem como um dos mais longevos. No ano em que completou 90 anos (2007), o autor de A Era dos Extremos lançou um novo livro. Em Globalização, Democracia e Terrorismo, Hobsbawm apresenta, em dez pequenos artigos, questões relevantes para entendermos os desdobramentos do mundo neste início de século XXI.

Como o próprio autor faz questão de ressaltar, o que se convencionou chamar de globalização não pode ser entendido como um tempo de igual divisão internacional política, econômica e militar entre os diferentes países. Os processos de intercâmbio comercial, informacional, cultural e financeiro são marcados pelas novas formas de relação desigual entre países.

Nesta obra, um conjunto de conferências e textos produzidos entre 2000 e 2006, o autor afirma que as questões centrais dizem respeito às

* Doutorando em Serviço Social pela Universidade Federal do Rio de Janeiro (UFRJ). Pesquisador do Coletivo de Estudos de Política Educacional (Escola Politécnica de Saúde Joaquim Venâncio - EPSJV / Fiocruz). E-mail: marcelaomelo@gmail.com 
[...] preocupações internacionais específicas desse período, que foi dominado pela decisão tomada pelo governo dos Estados Unidos em 2001 de afirmar uma hegemonia unilateral sobre o mundo, condenando convenções internacionais até então aceitas, reservando-se o direito de fazer guerras de agressão ou outras operações militares sempre que o desejasse e levando-as à prática (Hobsbawm, 2007, p. 13-14).

A conjuntura internacional após os eventos de 11 de setembro de 2001, como também a posição da economia norte-americana, com momentos de crises anunciadas, são fundamentais para a análise de nosso tempo.

A natureza das guerras e conflitos bélicos do século XXI é um tema central nessa obra, sobretudo, em um momento em que as diferenças entre combatentes e não-combatentes são diluídas, fato provado pela grande percentagem de mortos nas guerras atuais ser de civis não envolvidos diretamente na guerra. Comparando os dados sobre mortes das duas Grandes Guerras Mundiais e das guerras atuais, Hobsbawm mostra como, atualmente, mais de $80 \%$ dos mortos e atingidos em uma guerra são não-combatentes, o que contrasta fortemente com os números relativos aos conflitos já citados. Como afirma o autor:

No início do século XXI, encontramo-nos num mundo em que as operações armadas já não estão essencialmente nas mãos dos governos ou dos seus agentes autorizados, e as partes distantes não têm características, status e objetivos em comum, exceto quanto à vontade de utilizar a violência (ibid., p. 23).

Para nosso autor, as razões para tal mudança estariam no fato de que,

[...] a partir do fim da guerra fria, porque a maioria das operações militares desde então não foi conduzida por exércitos regulares, e sim por grupos diminutos de soldados, regulares ou não, operando, em muitos casos, armas de alta tecnologia e protegidos contra o risco de sofrer baixas (ibid., p. 24), 
o potencial destrutivo se intensifica, sobretudo, com danos sérios para os não-envolvidos.

Se podemos afirmar que há uma diminuição dos conflitos entre países, no início do século XXI, também é possível afirmar que aumentaram drasticamente os conflitos armados internos em muitos países do mundo. As preocupações com a natureza, as mudanças e as conseqüências das formas contemporâneas de guerra são desenvolvidas nos dois primeiros capítulos do livro.

A natureza dos conflitos e das guerras do último quartel mostra uma característica: uma inegável diminuição dos choques entre países e menos ainda disputas envolvendo a definição de fronteiras internacionais. Por outro lado, têm sido recorrentes distúrbios internos em que há participação de outros países, seja em ações unilaterais/individuais ou mediante ações conjuntas de vários Estados sob a coordenação da Organização das Nações Unidas (ONU), da Organização do Tratado do Atlântico Norte (Otan) ou mesmo de um país que esteja no comando, mas com soldados de muitas nacionalidades.

Em seguida, nos caps. 3 e 4, Hobsbawm inicia uma discussão acerca da especificidade da dominação estadunidense em nosso tempo. Reconhecendo características imperiais no papel que os Estados Unidos desempenham no sistema internacional, o autor aponta a necessidade de não se confundir essa atuação com a de outros impérios, não só de épocas pré-capitalistas, como também do século XIX e início do século passado, como foi o caso do império britânico.

Ao mesmo tempo, este início de século XXI ratifica os indícios de que, com o fim da União das Repúblicas Socialistas Soviéticas (URSS), os Estados Unidos assumem a conotação de única superpotência mundial, em termos de capacidade militar, 
política e econômica, ainda que, neste último tópico, haja indícios de que a China possa vir a ameaçar a liderança estadunidense.

Todos os perigos dessa condição têm sido provados pelas incursões dos Estados Unidos, sobretudo, a partir do 11 de Setembro. A ânsia imperialista assume um caráter mais público e menos "eufemizado" com as ações observadas ao longo da década, mas não pode ser ignorada, de modo algum, a contribuição dos outros países nesse sentido. Tem sido alardeado quase que semanalmente não apenas o papel desempenhado pela Inglaterra, sobretudo nos anos Tony Blair, como também o de outros países europeus e asiáticos, como corolários dessa nova ordem mundial. Ainda que se observem algumas fissuras nesse bloco, como a rejeição russa ao programa militar de uma base de lançamentos de mísseis de longo alcance a ser implantada pelos norte-americanos próxima a seu território, isso não é suficiente para sequer arranhar a liderança e a condução do processo.

Nem mesmo os organismos internacionais têm força para tentar barrar essa dominação unilateral estadunidense, embora tenhamos provas recorrentes de que, em momento algum, esse tenha sido o objetivo de algum deles. Como afirma Hobsbawm acerca de organismos como Banco Mundial, Organização Mundial do Comércio, Fundo Monetário Internacional, Nações Unidas,

Nenhum desses órgãos tem algum poder efetivo além daquele que lhes é conferido voluntariamente pelos Estados, ou por acordos entre eles, ou graças ao apoio de países poderosos. [...] Como apenas os Estados têm poder real, o risco é que as instituições internacionais se mostrem ineficazes ou carentes de legitimidade ao tentarem lidar com questões como os crimes de guerra (ibid., p. 29).

A especificidade do papel de relevo ocupado pelos Estados Unidos, hoje, na dinâmica de funcionamento do sistema capitalista mundial não advém apenas de seu inconteste poderio militar. Ser a economia-chefe do mundo, com enorme peso em todo o processo de 
funcionamento do sistema econômico mundial, com impactos em todos os grandes indicadores econômicos de nosso tempo, permite aos Estados Unidos exercer um papel central nesse sentido. Como afirma Hobsbawm (2007), isso confere uma especificidade para o tipo de imperialismo praticado pelos Estados Unidos nos séculos XX e XXI, o que lhes permite, inclusive, ser um caso único de grande império devedor, haja vista seus recorrentes déficits na balança comercial e conta corrente.

No cap. 5, Hobsbawm se dedica a uma temática por muitos considerada fora de lugar com a globalização: a nação e o nacionalismo no século XXI, que dá nome ao capítulo. Aqui, temas como migração em massa, xenofobia, identidade nacional e cultural são analisados por ele. Como pano de fundo, o autor de História Social do Jazz analisa o futebol como portador de um duplo potencial de identificação coletiva. Em nível local, os clubes regionais desempenham tal função, assim como as seleções nacionais, em nível mundial. Contudo, afirma o autor, a intensificação do mercado mundial de jogadores, como também dos próprios clubes, faz com que conflitos econômicos e empresariais sejam a tônica desse esporte em nosso tempo, embora não apenas dele. Assim, é possível entender que

[...] o negócio global do futebol é dominado pelo imperialismo de umas poucas empresas capitalistas com nomes de marcas também globais - um pequeno número de superclubes baseados em alguns países da Europa, que competem entre si tanto nas ligas nacionais quanto, preferivelmente, nas internacionais. Seus jogadores são recrutados em todo o mundo (ibid., p. 93).

Nos caps. 6 e 7, o debate gira em torno da questão da democracia no século XXI. O reconhecimento de sua suposta universalidade faz com que Hobsbawm se dedique a apresentar como não é possível esquecer que os chamados regimes democráticos contemporâneos não abrem mão de formas de dominação e exploração, tanto interna 
como externamente. Assim como se nota uma expansão de regimes formalmente democráticos pelo mundo, observa-se um movimento de separação e afastamento dos cidadãos comuns dos processos políticos, salvo um diminuto envolvimento em processos eleitorais, sendo que estes também estão em declínio.

A desqualificação da política se conjuga com a diminuição crescente do interesse do conjunto da população pela participação política stricto sensu. Como diz Hobsbawm (2007), se o critério primeiro da democracia representativa e sua conseqüente legitimidade têm sido a eleição popular, fica a pergunta da representatividade de um processo que envolve cada vez menos o conjunto da população:

[...] houve um declínio na vontade dos cidadãos de participar da política, assim como na efetividade da maneira clássica - a única legítima, segundo a teoria convencional - de exercer a cidadania, ou seja, a eleição, por sufrágio universal, dos que representam 'o povo' e estão por isso mesmo autorizados a governar em seu nome. Entre as eleições - ou seja, por vários anos, normalmente -, a democracia existe apenas como ameaça potencial à sua reeleição ou à dos seus partidos (ibid., p. 107).

Nesse contexto, para consolidação e manutenção da dominação burguesa, nada mais funcional do que manter as tomadas de decisão longe dos olhos do público, ou, então, próximo, mas em uma linguagem hermética e incompreensível.

O terceiro aspecto do título do livro, Terrorismo, é o tema dos caps. 8 e 9, com a preocupação central de analisar as mudanças no terrorismo político do fim do século XX, motivo de interrogação para nosso autor. Para além da abordagem mais comum do tema, Hobsbawm resgata debates acerca dos grupos que buscavam fazer política por meio de ações terroristas no mundo, como Sendero Luminoso (Peru), Brigadas Vermelhas (Itália), Pátria Basca e Liberdade (ETA, da Espanha), Exército Republicano Irlandês (IRA), além de outros, sobretudo para marcar a diferença com a lógica de 
ação da Al-Qaeda, ainda que igualmente condenáveis. Aqui, o autor chama atenção para o fato de que, a despeito da publicidade das ações dos grupos terroristas mais recentes, bem como dos eventos ocorridos em Nova York, Madrid e Londres, o sistema internacional de poder - bem como as estruturais internas - não foi sequer abalado por tais atos. Como afirma o autor,

[...] se ocorreram efeitos negativos posteriores, eles não se deveram as ações dos terroristas, mas sim à do governo Americano. [...] isso ressalta a fraqueza relativa e absoluta dos movimentos terroristas da fase atual. Eles são sintomas, e não agentes históricos significativos [...]. Operando em países estáveis, com regimes estáveis e sem apoio de setores relevantes da população, eles são um problema policial e não militar (ibid., p. 135).

Por último, mas não menos importante, nosso autor retoma a análise sobre o imperialismo estadunidense em nosso tempo. Começando pelo reconhecimento de que "os Estados nacionais ainda são dominantes", Hobsbawm afirma que o império norteamericano tem não apenas pretensões, mas necessidade de operar em todo o globo. O próprio autor, porém, alerta que os Estados Unidos nunca exerceram um colonialismo clássico, visto terem ocupado diretamente outros países apenas por curto período de tempo. Sua lógica de atuação sempre foi mediante países dependentes e satélites, com apoio de governantes eleitos ou não, mas com forte apoio norteamericano.

O que torna nosso tempo mais dramático é a inexistência de qualquer outra potência capaz de fazer frente, militar e economicamente, contra os Estados Unidos, o que deve perdurar por algum tempo, que não é possível determinar. Enquanto isso, o perigo da desestabilização política do mundo é real, até mesmo pela natureza e voracidade recente das ações e gestões norte-americanas em contextos em que seus interesses são contrariados em qualquer parte do globo. A doutrina de guerra preventiva adotada por George W. Bush é seu retrato mais fiel. Hobsbawm, entretanto, defende que 
o imperialismo norte-americano pode não ser tão duradouro, em vista da fragilidade da economia estadunidense.

Contudo, as possibilidades de salto para a frente no sentido de aprofundamento da lógica de exploração, combinada com essa inconteste supremacia militar, abrem portas para um futuro muito pouco róseo. É isso que o novo livro do mestre Eric Hobsbawm nos lega. Ainda que menos brilhante do que A Era dos Extremos e do que sua magistral biografia Tempos Interessantes, este novo livro nos fornece relevantes questões para entendermos nosso tempo. Às portas de completar 91 anos, Eric Hobsbawm, mais uma vez, acerta na mosca. 